\title{
Bio-banding in junior soccer players: a pilot study
}

\author{
Michael Romann ${ }^{*} \mathbb{D}$, Dennis Lüdin and Dennis-Peter Born
}

\begin{abstract}
Objective: Bio-banding (BB) has been introduced to account for varying maturity and to improve the talent development of junior soccer players. To date, research that investigated the physiological and technical effects of BB is sparse. Therefore, the aim of the study was to compare effects of BB with CA on selected technical and tactical parameters in U13 and U14 soccer players.

Results: BB significantly increased the number of duels $(p=0.024)$ and set pieces $(p=0.025)$ compared to chronological age. The mean time of ball possession per action was reduced $(p=0.021)$ and the rate of successful passes was lower with $\mathrm{BB}(p=0.001)$. Meanwhile, the total number of passes was unaffected $(p=0.796)$, and there was a trend towards a lower difference in ball possession between BB teams $(p=0.058)$. In addition, BB reduced the distances covered while jogging $(p=0.001)$, running $(p=0.038)$ and high-speed running $(p=0.035)$. With BB, an increased number of duels, unsuccessful passes and set pieces resulted in a quicker change of match play situations between teams. While physical demand was reduced, BB seems to result in a more technically and tactically challenging game. Benefits in long-term player development, however, require further investigation.
\end{abstract}

Keywords: Talent development, Maturation, Puberty, Youth sport, Youth competition

\section{Introduction}

The biological age (BA) of soccer players shows a large variation during puberty [1]. Early maturing players tend to dominate match play due to superior physical abilities, i.e. running speed, body height and mass [1], and they are promoted more likely in the talent selection process. In U16 academy soccer players, for instance, $50 \%$ were early and only $1.9 \%$ late maturing individuals [2]. However, late maturing players catch up with their biological development and might even overtake early developed counterparts with superior technical [3] and psychological skills [4] when not being deselected and lost at an earlier stage of talent selection $[5,6]$. To account for varying maturation, junior soccer players might be grouped by BA rather than chronological age (CA) for training and competition

*Correspondence: michael.romann@baspo.admin.ch Department for Elite Sport, Swiss Federal Institute of Sport Magglingen, Alpenstrasse 18, 2532 Magglingen, Switzerland
$[1,7]$. So-called bio-banding (BB) might help to overcome variations in maturity and might benefit both late and early maturing players. During BB matches, late maturing players perceived a reduced injury risk $[2,4]$, despite being involved in more tackles [8]. In addition, they had better chances to demonstrate their technical and tactical abilities [2, 4]. For early maturing players, BB provided more technical challenges that might aid in the holistic development of soccer talents [2, 4]. In previous studies, players were bio-banded over a wide range of age groups (11-15 years [8] and 9-15 years [2]), which might be practical for large clubs and soccer academies. Smaller clubs, however, do not have access to such a large number of players. In addition, in most countries, soccer teams are composed over a 2-year age span. Therefore, as recommended previously $[1,7]$, the aim of the study was to compare effects of BB with CA on selected technical and tactical parameters in U13 and U14 soccer players.

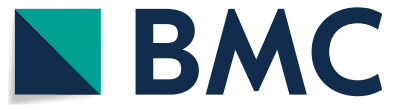

(c) The Author(s) 2020. This article is licensed under a Creative Commons Attribution 4.0 International License, which permits use, sharing, adaptation, distribution and reproduction in any medium or format, as long as you give appropriate credit to the original author(s) and the source, provide a link to the Creative Commons licence, and indicate if changes were made. The images or other third party material in this article are included in the article's Creative Commons licence, unless indicated otherwise in a credit line to the material. If material is not included in the article's Creative Commons licence and your intended use is not permitted by statutory regulation or exceeds the permitted use, you will need to obtain permission directly from the copyright holder. To view a copy of this licence, visit http://creativeco mmons.org/licenses/by/4.0/. The Creative Commons Public Domain Dedication waiver (http://creativecommons.org/publicdomain/ zero/1.0/) applies to the data made available in this article, unless otherwise stated in a credit line to the data. 


\section{Main text \\ Methods \\ Participants}

The present pilot study assessed BB based on practical considerations in a paired crossover design. In total, $\mathrm{n}=33$ U13 soccer players (32 male, 1 female; body height: $151 \pm 8 \mathrm{~cm}$, body mass: $38 \pm 6 \mathrm{~kg}$, age: $12.2 \pm 0.3$ years, maturity offset: $-1.6 \pm 0.8$ years $)$ and $\mathrm{n}=29 \mathrm{U14}$ soccer players ( 28 male, 1 female, $157 \pm 6 \mathrm{~cm}$, $45 \pm 5 \mathrm{~kg}, 13.2 \pm 0.4$ years, $-0.8 \pm 0.6$ years) were evaluated. All players were recruited from two elite soccer clubs participating in the Swiss talent development programme [9]. The programme represents the national top $2000 \mathrm{U} 13$ and top $1200 \mathrm{U} 14$ players. All players from the present study participated for at least $4.3 \pm 0.7$ years in structured and regular soccer practice and match play. After ethical approval (Swiss Federal Institute of Sport; Nr. 2018/057), all participants and their legal guardians signed written informed consent to participate. The study was conducted in accordance with the guidelines of the Declaration of Helsinki.

\section{Procedures \\ Bio-banding}

Maturity offset (MO), age at peak height velocity (APHV) and percentage of adult height were assessed by measuring body weight, standing height and sitting height using a body scale (Seca 876, Seca, Hamburg, Germany) and a stadiometer (Seca 217, Seca, Hamburg, Germany; Mirwald, 2002; Sherar, 2005). Subsequently, all male players were ranked based on their MO. The ranking was split at its median and the biologically younger half assigned to team BA1 (MO: -2.5 to -1.2 years) and biological older half to BA2 (MO: -1.2 to 0.0 years). Both female players were on-time maturing and therefore stayed with their team. With respect to practical considerations and previous recommendations [1,7], team coaches evaluated each player's technique, game intelligence, personality and playing speed (TIPS) [10-12]. TIPS is the talent identification instrument invented by Ajax Amsterdam. The model has been mirrored by several clubs of the English Premier League and the Swiss Football Association. Based on the coaches' evaluation, two players from BA1 were assigned to BA2 due to their superior technical and tactical abilities. Two players from BA2 still had to catch up with their technical and tactical skills and were assigned to BA1.

\section{Match play}

After a two-month familiarisation period with BB training sessions and matches, eight 20-min matches were carried out on two natural grass pitches (size: $55 \times 58 \mathrm{~m}$ ). The first and fourth 20-min matches were played with
$\mathrm{BB}$, while the second and third 20-min matches were played with conventional CA groups (U13 and U14). The matches were video-captured ball-oriented (focused on the ball) for a subsequent analysis of technical and tactical parameters. The camera was positioned near the middle line of the pitch at a height of 3.5 meters above the ground. Video data were coded and analysed using DartFish Note (Dartfish, Fribourg, Switzerland). Technical and tactical parameters were defined beforehand by an expert group of the Swiss Football Association. These parameters were: difference in ball possession between teams (\% p.), mean time of ball possession per action (s), changes in ball possession (n), shots (n), successful goal attempts (\%), passes (n) (successful\% vs unsuccessful\%), duels (n), fouls (n) and set pieces (n) which were subdivided by goal kicks, throw-ins, free kicks and penalty kicks. Physical parameters were measured using global positioning data (FieldWiz, Sensitech AG, Goldach, Switzerland) collected with $18-\mathrm{Hz}$. Because some players were substituted between matches, 49 of 72 possible paired subjects playing both $\mathrm{BB}$ and $\mathrm{CA}$ matches were used for the analysis. Based on previous recommendations, running distances were analysed for walking, jogging, running, high-speed running and sprinting at $0-5.8 \mathrm{~km} / \mathrm{h}, 5.8-11.5 \mathrm{~km} / \mathrm{h}, 11.5-15.8 \mathrm{~km} / \mathrm{h}, 15.8-$ $20.0 \mathrm{~km} / \mathrm{h}$ and $>20.0 \mathrm{~km} / \mathrm{h}$, respectively [13].

\section{Statistical analysis}

All data are presented as mean \pm standard deviation (SD). All matches were divided into 5-min intervals, from which mean values were used to compare differences between BB and CA using a t-test. Wilcoxon's signedrank test was applied for all non-normally distributed data (Shapiro-Wilk test). Cohen's $d$ effect sizes were calculated [14] and regarded as small $(<0.2)$, medium $(<0.6)$ and large $(<1.2)$ [15]. Statistically significant differences were analysed with SPSS 25.0 (IBM Corp., Armonk, NY, USA) and an alpha level of 0.05 .

\section{Results \\ Anthropometrical and physical parameters}

MO $(-1.69 \pm 0.74$ and $-0.74 \pm 0.59$ years; $p<0.001$, $d=1.42)$ and percentage of adult height $(83.6 \pm 1.6 \%$ and $87.8 \pm 2.8 \% ; p=0.008, d=1.24$ ) were significantly different between the $\mathrm{BB}$ teams $\mathrm{BA} 1$ and $\mathrm{BA} 2$, respectively. APHV $(13.96 \pm 0.59$ and $13.79 \pm 0.40$ years; $p=0.197, d=0.31$ ) were similar in both groups. Physical data are presented in Fig. 1. BB reduced the total running distance $(1.83 \pm 0.40$ and $1.94 \pm 0.39 \mathrm{~km}$; $p<0.001, d=0.26)$, as well as distances covered jogging $(0.69 \pm 0.24$ and $0.75 \pm 0.25 \mathrm{~km} ; p<0.001, d=0.25)$, running $(0.30 \pm 0.13$ and $0.32 \pm 0.14 \mathrm{~km} ; p=0.038$, $d=0.22)$ and high-speed running $(0.11 \pm 0.06$ and 


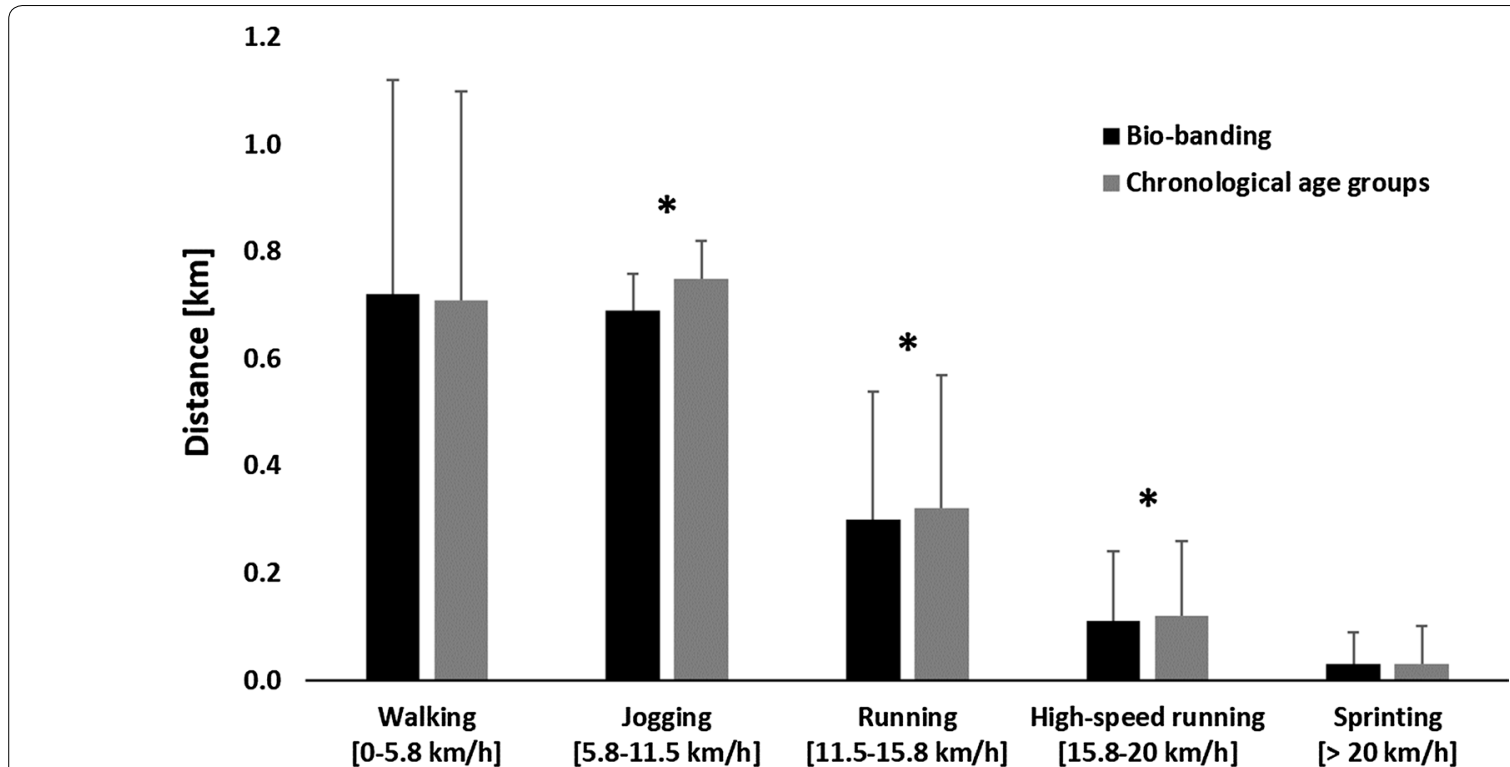

Fig. 1 Physical parameters for bio-banded compared to conventional match play. *Significant difference between groups

$0.12 \pm 0.07 \mathrm{~km} ; p=0.035, d=0.25)$ compared to CA, respectively. Distances for walking $(0.72 \pm 0.07$ and $0.71 \pm 0.07 \mathrm{~km} ; p=0.714, d=0.05)$, sprinting $(0.03 \pm 0.03$ and $0.03 \pm 0.03 \mathrm{~km} ; p=0.436, d=0.13)$, maximal running velocity $(22.19 \pm 3.07$ and $21.98 \pm 2.57 \mathrm{~km} / \mathrm{h}, p=0.567$, $d=0.07)$ and maximal accelerations $(4.11 \pm 0.40$ and $\left.4.08 \pm 0.38 \mathrm{~m} / \mathrm{s}^{2}, \quad p=0.700, d=0.06\right)$ were similar between $\mathrm{BB}$ and $\mathrm{CA}$.

\section{Technical and tactical parameters}

Compared to the $\mathrm{CA}$ match play, $\mathrm{BB}$ significantly increased the number of duels $(\mathrm{p}=0.024 ; d=0.89)$ and set pieces $(\mathrm{p}=0.025 ; d=1.00)$, while the mean time of ball possession per action $(\mathrm{p}=0.021 ; d=0.62)$ was reduced. The rate of successful passes $(\mathrm{p}<0.001 ; d=1.24)$ was lower and the rate of unsuccessful passes $(\mathrm{p}<0.001$; $d=1.06$ ) was higher with $\mathrm{BB}$, but the number of passes remained unaffected. A trend towards a lower difference in ball possession between bio-banded teams was evident $(p=0.058 ; d=0.69)$. The remaining technical and tactical parameters were similar between the BB and CA conditions (Table 1).

\section{Discussion}

The main findings of the study were that $\mathrm{BB}$ reduced distances covered in jogging, running and highspeed running compared to CA. Technical and tactical parameters showed an increased number of

Table 1 Technical and tactical parameters for bio-banded compared to conventional match play based on chronological age (CA) groups

\begin{tabular}{|c|c|c|c|c|c|}
\hline Parameter & BB & CA & $p$-value & $95 \% \mathrm{Cl}$ & Cohen's $d$ \\
\hline Duels $[n]$ & $6.8 \pm 3.4$ & $4.4 \pm 1.7$ & 0.02 & {$[0.4,4.4]$} & 0.89 \\
\hline Difference in ball possession between teams [\% p.] & $6.0 \pm 16.0$ & $18.8 \pm 20.6$ & 0.06 & {$[-26.1,0.5]$} & 0.69 \\
\hline Mean time of ball possession per action [s] & $10.7 \pm 2.7$ & $12.4 \pm 2.7$ & 0.02 & {$[-3.0,-0.3]$} & 0.62 \\
\hline Changes in ball possession $[n]$ & $30.4 \pm 8.3$ & $26.3 \pm 6.6$ & 0.08 & {$[-0.5,8.8]$} & 0.55 \\
\hline Fouls $[n]$ & $1.1 \pm 0.9$ & $1.3 \pm 1.3$ & 0.57 & {$[-0.9,0.5]$} & 0.17 \\
\hline Set pieces $[n]$ & $10.3 \pm 2.9$ & $7.5 \pm 2.6$ & 0.03 & {$[0.4,5.1]$} & 1.00 \\
\hline Shots $[n]$ & $3.4 \pm 2.0$ & $3.8 \pm 1.8$ & 0.53 & {$[-1.6,0.9]$} & 0.20 \\
\hline Successful goal attempts [\%] & $30.3 \pm 38.6$ & $25.6 \pm 23.1$ & 0.76 & {$[-14.6,23.9]$} & 0.15 \\
\hline Passes $[n]$ & $41.4 \pm 7.5$ & $40.6 \pm 10.9$ & 0.80 & {$[-6.2,8.0]$} & 0.09 \\
\hline Successful passes [\%] & $65.3 \pm 8.2$ & $74.5 \pm 6.6$ & $<0.01$ & {$[-14.1,-4.3]$} & 1.23 \\
\hline Unsuccessful passes [\%] & $34.7 \pm 8.2$ & $25.5 \pm 6.6$ & $<0.01$ & {$[3.8,14.6]$} & 1.06 \\
\hline
\end{tabular}


duels $(\mathrm{p}=0.024 ; d=0.89)$ and set pieces $(\mathrm{p}=0.025$; $d=1.00$ ), while the mean time in ball possession per action $(\mathrm{p}=0.021 ; d=0.62)$ was reduced. The total number of passes was unaffected, but the rate of successful passes $(\mathrm{p}<0.001 ; d=1.24)$ was lower and the rate of unsuccessful passes $(\mathrm{p}<0.001 ; d=1.06)$ higher. There was a trend towards a lower difference in ball possession $(p=0.058 ; d=0.69)$ between bio-banded teams.

Previous studies showed that $\mathrm{BB}$ reduces the dominance and physical advantage of early maturing players $[1,8]$, which have to strive to development better their technical and tactical skills to keep up with physically equal opponents [7]. Late maturing players, on the other hand, participate more actively in match play and perceive more options to show leadership $[2,4]$. With higher self-confidence [4] and a reduced perception of injury risk [2], late maturing players are involved in more tackles [8].

The quicker change of match play situations between bio-banded teams in the present study was visible with the reduced time of ball possession per action and difference in ball possession between teams. The larger involvement of late maturing players and the reduced dominance of early maturing players in BB might result in a more technically and tactically challenging game. While the total number of passes remained unaffected, the number of unsuccessful passes was increased at the cost of successful passes. In addition, the number of duels and set pieces increased. The increase variation of match play situations between $\mathrm{BB}$ and conventional in the short term might however provide additional opportunities for skill acquisition over the long run $[8,16]$. With greater involvement of late maturing players and higher technical and tactical challenges for early maturing players, a more variable match play between bio-banded teams might aid in the development of technical and tactical skills of young soccer talents [4].

In addition, the match play in $\mathrm{BB}$ seems to result in quicker ball movement. Previous studies showed a higher number of short passes, fewer dribbles and fewer long passes with BB [8]. The shift towards a quicker and more technically and tactically challenging game reduces, conversely, perceived exertion among late maturing players [8]. These findings are supported with the present study, showing reduced running distances among various submaximal velocities. While the reduced physical demand can be compensated with specific conditioning regimes, BB aids in developing specific on-ball actions, i.e. duels and set pieces.

\section{Conclusion}

$\mathrm{BB}$ results in a quicker change of match play situations with a reduced difference in ball possession between teams and reduced time of ball possession per action. The increased number of duels, unsuccessful passes and set pieces seem to result from a quicker match play and higher involvement of late maturing players. While physical demand is reduced for the benefit of more technical and tactical match play, BB might support the development of technical and tactical skills in youth soccer.

\section{Limitations}

While the nature of team sports involves the exchange of players during match play, future studies would benefit from a strict paired crossover design using the same positions in all matches. This would also enable analyses of the technical, tactical and physical parameters specific to playing position and maturity status. In addition, future studies need to evaluate the long-term effects, the influences of team interaction and the optimal time point and dose for its application of $\mathrm{BB}$ in youth soccer.

\section{Abbreviations}

APHV: Age at peak height velocity; BA: Biological age; BB: Bio-banding; CA: Chronological age; MO: Maturity offset.

\section{Acknowledgements}

The authors thank club staff and players for their participation and effort. Furthermore, we want to acknowledge Stefan Brunner and Raphael Kern of the Swiss Football Association for their support.

\section{Authors' contributions}

$M R, D L$ and DPB contributed to planning the study. DL collected all data. All authors drafted the manuscript and analysed the data, contributed to interpreting the data and approved the final version of the manuscript. All authors read and approved the final manuscript.

\section{Funding}

There were no specific grants or funding for the present pilot study.

\section{Availability of data and materials}

All data are available on request.

\section{Ethical approval and consent to participate}

After ethical approval (Swiss Federal Institute of Sport; Nr. 2018/057), all participants and their legal guardians signed written informed consent to participate. The study was conducted in accordance with the guidelines of the Declaration of Helsinki.

\section{Consent for publication}

Not applicable.

\section{Competing interests \\ There are no competing interests.}

Received: 11 February 2020 Accepted: 3 May 2020

Published online: 12 May 2020 


\section{References}

1. Malina RM, Cumming SP, Rogol AD, Coelho-e-Silva MJ, Figueiredo AJ, Konarski JM, Kozieł SM. Bio-banding in youth sports: background, concept, and application. Sports Med. 2019;49:1-15.

2. Bradley B, Johnson D, Hill M, McGee D, Kana-Ah A, Sharpin C, Sharp P, Kelly A, Cumming SP, Malina RM. Bio-banding in academy football: player's perceptions of a maturity matched tournament. Ann Hum Biol. 2019;46(5):400-8.

3. Zuber C, Zibung M, Conzelmann A. Holistic patterns as an instrument for predicting the performance of promising young soccer players-a 3-years longitudinal study. Front Psychol. 2016;7:1088.

4. Cumming SP, Searle C, Hemsley JK, Haswell F, Edwards H, Scott S, Gross A, Ryan D, Lewis J, White P. Biological maturation, relative age and selfregulation in male professional academy soccer players: a test of the underdog hypothesis. Psychol Sport Exerc. 2018;39:147-53.

5. Carling C, le Gall F, Reilly T, Williams AM. Do anthropometric and fitness characteristics vary according to birth date distribution in elite youth academy soccer players? Scand J Med Sci Sports. 2009;19(1):3-9.

6. Gibbs BG, Jarvis JA, Dufur MJ. The rise of the underdog? The relative age effect reversal among Canadian-born NHL hockey players: a reply to Nolan and Howell. Int Rev Sociol Sport. 2012;47(5):644-9.

7. Cumming SP, Lloyd RS, Oliver JL, Eisenmann JC, Malina RM. Bio-banding in sport: applications to competition, talent identification, and strength and conditioning of youth athletes. Strength Cond J. 2017;39(2):34-47.

8. Abbott W, Williams S, Brickley G, Smeeton NJ. Effects of bio-banding upon physical and technical performance during soccer competition: a preliminary analysis. Sci Period Res Tech Sport. 2019;7(8):193.
9. Romann M, Rössler R, Javet M, Faude O. Relative age effects in Swiss talent development-a nationwide analysis of all sports. J Sports Sci. 2018:38:1-7.

10. Romann M, Javet M, Fuchslocher J. Coache's eye as a valid method to assess biological maturation in youth elite soccer. Talent Dev Excell. 2017;9:3-13.

11. Tschopp M, Biedert R, Seiler R, Hasler H, Marti B: Predicting success in Swiss junior elite soccer players: a multidisciplinary 4-year prospective study. In: 5th World Congress on Science and Football: 2003; Lisbon; 2003.

12. Brown J. Sports talent: How to indetify and develop outstanding athlet. Campaign: Human Kinetics; 2001

13. Harley JA, Barnes CA, Portas M, Lovell R, Barrett S, Paul D, Weston M. Motion analysis of match-play in elite U12 to U16 age-group soccer players. J Sports Sci. 2010;28(13):1391-7.

14. Fröhlich $M$, Emrich $E$, Pieter A, Stark R. Outcome effects and effects sizes in sport sciences. Int J Sports Sci Eng. 2009;3(3):175-9.

15. Hopkins W, Marshall S, Batterham A, Hanin J. Progressive statistics for studies in sports medicine and exercise science. Med Sci Sports Exerc 2009;41(1):3.

16. Davids K, Glazier P, Araujo D, Bartlett R. Movement systems as dynamical systems. Sports Med. 2003;33(4):245-60.

\section{Publisher's Note}

Springer Nature remains neutral with regard to jurisdictional claims in published maps and institutional affiliations.
Ready to submit your research? Choose BMC and benefit from:

- fast, convenient online submission

- thorough peer review by experienced researchers in your field

- rapid publication on acceptance

- support for research data, including large and complex data types

- gold Open Access which fosters wider collaboration and increased citations

- maximum visibility for your research: over $100 \mathrm{M}$ website views per year

At BMC, research is always in progress.

Learn more biomedcentral.com/submissions 